\title{
Helix-Inversion Equilibrium of Isotactic Chloral Oligomers in Solution
}

\author{
Koichi Ute, Katsuo Hirose, Hiroaki Kashimoto, \\ Hiroko Nakayama, Koichi Hatada, ${ }^{\dagger}$ \\ and Otto VoGL* \\ Department of Chemistry, Faculty of Engineering Science, \\ Osaka University, Toyonaka, Osaka 560, Japan \\ * Polytechnic University, Six MetroTech Center, \\ Brooklyn, NY, 11201, U. S. A.
}

(Received April 16, 1993)

\begin{abstract}
The conformational equilibrium of the purely isotactic oligomers of chloral, $\mathrm{CH}_{3} \mathrm{O}\left[\mathrm{CH}\left(\mathrm{CCl}_{3}\right) \mathrm{O}\right]_{n} \mathrm{R}\left(\mathrm{R}=\mathrm{CH}_{3}, \mathrm{C}_{2} \mathrm{H}_{5}, \mathrm{COCH}_{3} ; 3 \leq n \leq 8\right)$, has been investigated by means of $500 \mathrm{MHz}$ dynamic ${ }^{1} \mathrm{H}$ NMR spectroscopy in solution. The oligomers assumed the structure of a stable $4 / 1$ helix consisting of repeated gauche $(-)$-skew $(+)(\bar{g} s)$ or skew $(-)$-gauche $(+)(\bar{s} g)$ sequences along the acetal backbone. The interconversion between the right-handed $(\bar{g} s)_{n}$ and left-handed $(\bar{s} g)_{n}$ helices was slow enough for the NMR spectroscopy to distinguish clearly the two states. $\Delta H$ and $\Delta S$ between the two helical states of $\mathrm{CH}_{3} \mathrm{O}\left[\mathrm{CH}\left(\mathrm{CCl}_{3}\right) \mathrm{O}\right]_{6} \mathrm{C}_{2} \mathrm{H}_{5}$ were determined as 0.498 $\mathrm{kcal} / \mathrm{mo}^{-1}$ and $0.238 \mathrm{cal} \mathrm{K}^{-1} \mathrm{~mol}^{-1}$, respectively, and those of $\mathrm{CH}_{3} \mathrm{O}\left[\mathrm{CH}\left(\mathrm{CCl}_{3}\right) \mathrm{O}_{6} \mathrm{COCH}_{3}\right.$ as $-0.988 \mathrm{kcal} \mathrm{mol}^{-1}$ and $1.40 \mathrm{cal} \mathrm{K}^{-1} \mathrm{~mol}^{-1}$. The $\Delta H$ values were consistent with the results from molecular mechanics calculations. The activation energy for the helix-sense inversion $\left(\Delta G^{\ddagger}\right)$ has been found to depend on the degree of polymerization, $n$. The values were $8.2,12.7,16.4$, and $19.6 \mathrm{kcal} \mathrm{mol}^{-1}$ for the symmetrical oligomers $\left(\mathrm{R}=\mathrm{CH}_{3}\right)$ with $n=3,4,5$, and 6 , respectively. The linear increase of $\Delta G^{\neq}$with $n$ suggested that it should be possible to resolve the symmetrical "meso" oligomers higher than the hexamer into the optical antipodes at room temperature based entirely on conformational asymmetry; this supposition has been confirmed by chiral resolution using the HPLC technique with (+)-poly(triphenylmethyl methacrylate) as stationary phase.
\end{abstract}

KEY WORDS NMR Spectroscopy / Activation Energy / HPLC / Optical Resolution / Conformational Asymmetry / Helix / Terminal Group / Molecular Mechanics Calculation / Polychloral / Aldehyde Polymerization /

Some synthetic polymers such as polychloral, ${ }^{1-4}$ poly(triphenylmethyl methacrylate), ${ }^{5,6}$ poly(t-butyl isocyanide), ${ }^{7,8}$ and poly(quinoxaline-2,3-diyl)s ${ }^{9}$ are known to show optical activity arising from conformational asymmetry (one-handed helix) when the polymers are prepared by helix-sense selective polymerization. In some cases the one-handed helix of the polymers is rigid in solution ${ }^{6,7}$ or slowly undergoes racemization to a nearly $1: 1$ mixture of right-handed and left-handed

\footnotetext{
† To whom correspondence should be addressed.
}

helices. ${ }^{10}$ In other cases, ${ }^{11,12}$ the polymers are insoluble, but the optical rotation of the isotropic polymer films did not change even when annealing at higher temperatures. The helical conformation of polyisocyanates is less stable, and consequently, the two helical states exist in fast equilibrium. ${ }^{13,14}$ In spite of these findings, it has been difficult to get quantitative information of the stability of the one-handed helices, i.e., the kinetic and thermodynamic parameters for the helix-sense inversion ( $c f$. 


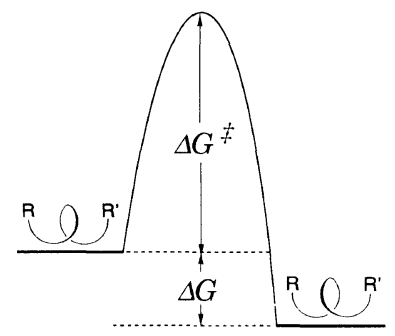

Figure 1. The equilibrium between the two helical states involved in the helix-sense inversion.

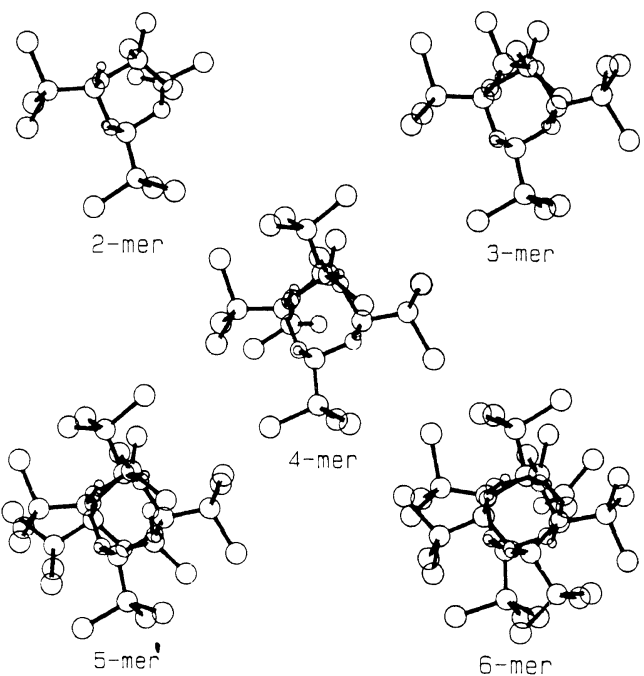

Figure 2. Structure of the isotactic chloral oligomers 1 from dimer to hexamer as indicated by single crystal X-ray analysis. Terminal groups are omitted for clarity.

Figure 1). Molecular weight dependence of these parameters still remains an open question.

Recently, we demonstrated that the $t$ butoxy-initiated, acetate end-capped, purely isotactic oligomers of chloral $\mathbf{1}$ form a stable helical structure in solution as well as in the crystalline state (Figure 2). ${ }^{15,16}$ These helical oligomers provide excellent examples for the evaluation of their conformational stabilities because they can be obtained as uniform compounds without any distribution in their structures. They have a high tendency to crystallize to prepare single crystals for X-ray crystallographic analysis; this family of com- pounds also gives very simple ${ }^{1} \mathrm{H}$ and ${ }^{13} \mathrm{C}$ NMR spectra.

The individual oligomers 1 from dimer to nonamer were resolved into the optical antipodes $(R, R, \cdots, R$ and $S, S, \cdots, S$ isomers) by a chiral HPLC technique. ${ }^{17}$ The $(R, R, R, R, R)-(-)$-pentamer $\quad\left([\alpha]_{\mathrm{D}}=-23.7^{\circ}\right)$ was found to adopt the right-handed $4 / 1$ helix approximating repeated gauche(-)-skew (+) $(\bar{g} s)$ sequences along the acetal backbone. ${ }^{16,18}$ The helix-sense preference derives from the difference of conformational energy $(\Delta G)$ between the right-handed $(\bar{g} s)_{5}$ and left-handed $(\bar{s} g)_{5}$ helices in equilibrium. The $\Delta G$ was estimated to be $2.7 \mathrm{kcal} \mathrm{mol}^{-1}$ by molecular mechanics calculation. Another chloral oligomer with a smaller $\Delta G$ (e.g., the methoxyinitiated, acetyl-terminated oligomer 2 or the ethoxy-initiated, methoxy-terminated oligomer 3) would make it possible to observe both helical states by spectroscopic methods.<smiles>[R]OC(C)C(C)OCC(=O)O</smiles>

\begin{tabular}{ccc} 
& $\mathrm{R}$ & $\mathrm{R}^{\prime}$ \\
\hline $\mathbf{1}$ & $t-\mathrm{C}_{4} \mathrm{H}_{9}$ & $\mathrm{COCH}_{3}$ \\
2 & $\mathrm{CH}_{3}$ & $\mathrm{COCH}_{3}$ \\
3 & $\mathrm{C}_{2} \mathrm{H}_{5}$ & $\mathrm{CH}_{3}$ \\
4 & $\mathrm{CH}_{3}$ & $\mathrm{CH}_{3}$
\end{tabular}

The purely-isotactic and symmetrical oligomer carrying a methyl group at both ends $\mathbf{4}$ is the "meso" isomers in which the right-handed and left-handed helices are no longer diastereomeric but enantiomeric states with equal probability of existence $(\Delta G=0)$. In the preceding communication, ${ }^{19}$ we reported the measurements of the activation energy for the helix-sense inversion $\left(\Delta G^{\ddagger}\right)$ of the oligomers 4 with a degree of polymerization $n=4$ and 5 .

The present paper aims to give a concrete description of the helix-inversion equilibrium of isotactic chloral oligomers in solution by determining $\Delta G$ and $\Delta G^{\neq}$for $\mathbf{2 - 4}$.

\section{EXPERIMENTAL}

The oligomers 2-4 were prepared by the 
cryotachensic polymerization $^{20-22}$ of chloral $(50 \mathrm{mmol})$ initiated with sodium methoxide or sodium ethoxide $(10 \mathrm{mmol})$ in toluene at $45^{\circ} \mathrm{C}$ and terminated with acetic anhydride or methyl trifluoromethanesulfonate $(20 \mathrm{mmol})$ at $10^{\circ} \mathrm{C}$. The individual oligomers from trimer to octamer were isolated from the oligomer mixtures by GPC or by preparative supercritical fluid chromatography (SFC). The procedures of SFC were described previously. ${ }^{23}$ Each oligomer was purified by crystallization from methanol containing a small amount of chloroform.

NMR spectra were recorded on a JEOL JNM-GX500 spectrometer in toluene- $d_{8}$ or nitrobenzene- $d_{5}$ under a dry nitrogen atmosphere.

Optical resolution of $\mathbf{4}$ was performed at $1{ }^{\circ} \mathrm{C}$ on a JASCO Trirotar-II chromatograph equipped with JASCO DIP-181C polarimetric $(\mathrm{Hg}$ lamp, without filter) and Shodex $\mathrm{RI}$ SE-61 refractive index detectors. The silicagel coated with $(+)$-poly(triphenylmethyl methacrylate $)^{24}$ was used as stationary phase (Chiralpak-OT(+), Daicel Chem. Ind. Ltd., column size $=4.6 \mathrm{~mm}$ i.d. $\times 250 \mathrm{~mm}$ ), and methanol was employed as mobile phase $\left(0.5 \mathrm{ml} \mathrm{min}^{-1}\right)$.

Molecular mechanics calculations were carried out by employing the MM2 force field program. ${ }^{25}$ The atomic coordinates for the $(R, R, R, R, R)$-(-)-pentamer of 1 , which were obtained by X-ray crystallographic determination, ${ }^{18}$ were modified to the structural parameter set for the initiation of iterative geometry optimization. Parameters and force constants are mostly provided in the MM2 program and used without modification. The calculations were conducted according to the procedures of Abe and his coworkers for the dimer and trimer of chloral. ${ }^{26}$ Since the molecules comprise many rotatable bonds, several local-minimum conformations which were essentially identical to the minimum conformation within $+0.1 \mathrm{kcal} \mathrm{mol}^{-1}$ were found for both right-handed and left-handed helical states.

\section{RESULTS AND DISCUSSION}

\section{Activation Energy for the Helix-Sense Inversion $\left(\Delta G^{\neq}\right)$}

Figure $3 \mathrm{a}$ shows the $500 \mathrm{MHz}{ }^{1} \mathrm{H}$ NMR spectrum of the pentamer of 4 measured in toluene- $d_{8}$ at $30^{\circ} \mathrm{C}$. The pentamer exhibited the signals due to the methyl groups at 3.08, $3.48 \mathrm{ppm}$ and those due to the acetal methine protons at 4.84, 5.46, 5.60,6.03 ppm; the peaks are relatively broad. The signal at $6.09 \mathrm{ppm}$ is sharp and is attributed to the acetal proton of the central monomer unit $\left(\mathrm{H}^{3}\right)$. The nonequivalency of the two methyl groups and of the five acetal protons indicates that the pentamer exists in a highly preferred conformation, i.e., the 4/1-helix approximating the repeat gauche $(-)$-skew $(+)(\bar{g} s)$ sequences (or the repeat $\bar{s} g$ sequences). The signals, except for the signal due to $\mathrm{H}^{3}$, became broader at $60^{\circ} \mathrm{C}$ (Figure $3 \mathrm{~b}$ ) and the methyl proton resonances coalesced at $72^{\circ} \mathrm{C}$ (Figure $3 \mathrm{c}$ ). The spectrum

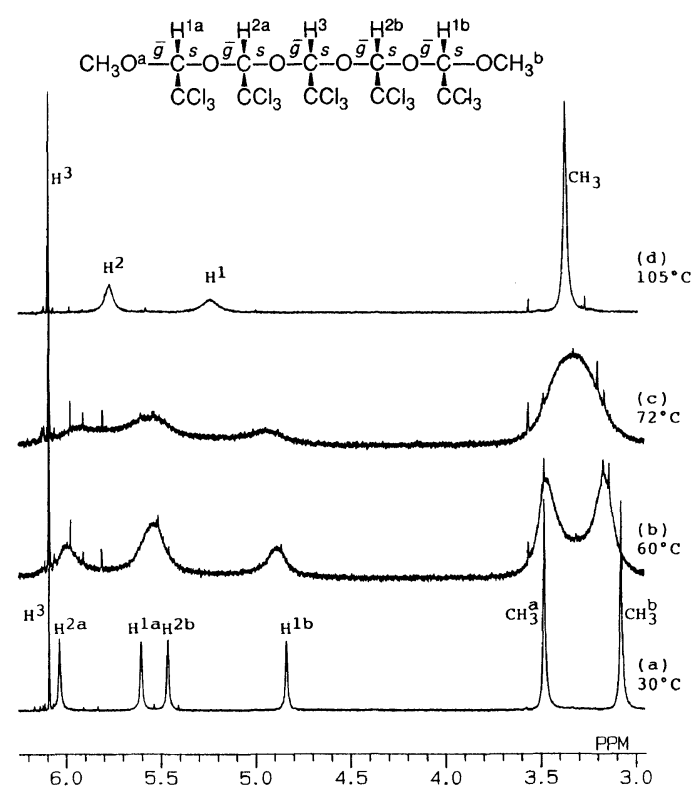

Figure 3. $500 \mathrm{MHz}{ }^{1} \mathrm{H}$ NMR spectra of the isotactic pentamer of 4 in toluene- $d_{8}$ at $30^{\circ} \mathrm{C} \mathrm{(a),} 60^{\circ} \mathrm{C}(\mathrm{b}), 72^{\circ} \mathrm{C}$ (c), and $105^{\circ} \mathrm{C}(\mathrm{d})$. 
(a) 6-mer at $70^{\circ} \mathrm{C}$

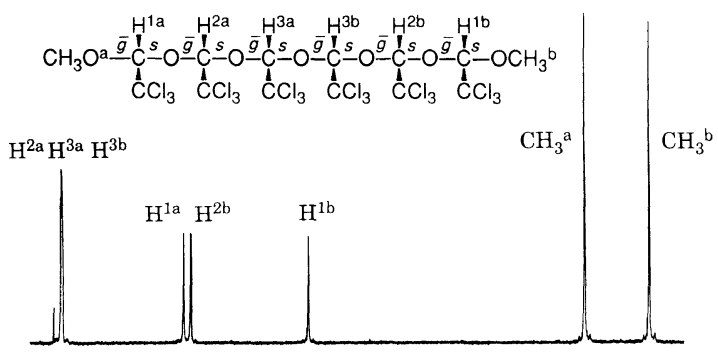

(b) 4-mer at $30^{\circ} \mathrm{C}$

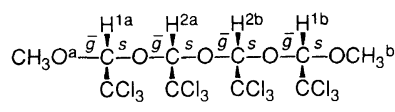

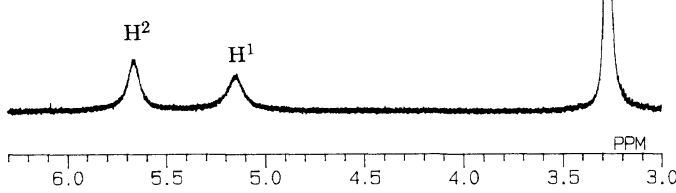

Figure 4. $500 \mathrm{MHz}{ }^{1} \mathrm{H}$ NMR spectra of the isotactic hexamer (a) and tetramer of 4 (b) measured in toluene- $d_{8}$ at $70^{\circ} \mathrm{C}$ and $30^{\circ} \mathrm{C}$, respectively.

appeared finally as four signals with an intensity ratio of $6: 2: 2: 1$ at $105^{\circ} \mathrm{C}$ (Figure $3 \mathrm{~d})$. Cooling the sample solution to $35^{\circ} \mathrm{C}$ again reproduced the spectrum shown in Figure $3 \mathrm{a}$. These results clearly show that the rate of helix-sense reversal becomes too fast at $72^{\circ} \mathrm{C}$ for the time-scale of the $500 \mathrm{MHz} \mathrm{NMR}$ to distinguish the two methyl groups on the $\bar{g}$ and $s$ sides. From the temperature dependence of the spectrum, $\Delta G^{\neq}$was determined as $16.4 \mathrm{kcal} \mathrm{mol}^{-1}$. Though the coalescence temperature $\left(T_{\mathrm{c}}\right)$ for the acetal proton resonances was somewhat higher $\left(\mathrm{ca} .80^{\circ} \mathrm{C}\right)$, the resonances had a larger shift difference $(\Delta v)$, and thus the $\Delta G^{\neq}$value estimated from these resonances ( $c a .16 .3 \mathrm{kcal} \mathrm{mol}^{-1}$ ) agreed with that determined from the methyl resonances.

The hexamer showed a total of eight singlets with narrow line width at 3.19, 3.52, 4.90, 5.49, 5.53 , and 6.13 (three singlets) ppm due to the two methyl groups and six acetal protons at
Table I. Observation of helix-sense inversion of the isotactic chloral oligomers 4 in toluene- $d_{8}$ by $500 \mathrm{MHz}{ }^{1} \mathrm{H}$ NMR

\begin{tabular}{|c|c|c|c|}
\hline \multirow{2}{*}{$n$} & $T_{\mathrm{c}}^{\mathrm{a}}$ & $\Delta v^{\mathrm{b}}$ & $\tau_{20}{ }^{c}$ \\
\hline & ${ }^{\circ} \mathrm{C}$ & $\mathrm{Hz}$ & $\mathrm{s}$ \\
\hline 3 & -98 & 103 & $2.0 \times 10^{-7}$ \\
\hline 4 & 4 & 245 & $4.9 \times 10^{-4}$ \\
\hline 5 & 72 & 141 & 0.26 \\
\hline 6 & $140^{d}$ & $172^{d}$ & 65 \\
\hline
\end{tabular}

${ }^{a}$ Coalescence temperature.

${ }^{b}$ Chemical shift between the non-equivalent methoxy resonances.

c Life time of the one-handed helical state at $20^{\circ} \mathrm{C}$. $(1 / \tau)=\left(k_{\mathrm{B}} T / h\right) \exp \left(\Delta G^{\neq} / R T\right)$ $\Delta G^{\neq}=R T_{\mathrm{c}} \ln \left[\sqrt{2} k_{\mathrm{B}} T_{\mathrm{c}} / \pi h(\Delta v)\right]$

d Measured in nitrobenzene- $d_{5}$.

$70^{\circ} \mathrm{C}$ (Figure 4a). This indicates that the helix of the hexamer is much more rigid than the helix of the pentamer. Since the $T_{\mathrm{c}}$ of the methyl proton resonances was higher than the boiling point of toluene- $d_{8}$, the $T_{\mathrm{c}}$ for the hexamer was determined in nitrobenzene- $d_{5}$ as $140^{\circ} \mathrm{C}$. On the other hand, the tetramer gave one methyl and two acetal resonances even at $30^{\circ} \mathrm{C}$ (Figure $4 \mathrm{~b})$. The $T_{\mathrm{c}}$ for the methyl proton resonances of the tetramer was determined as $4^{\circ} \mathrm{C} . \Delta G^{\neq}$ was calculated to be $12.7 \mathrm{kcal} \mathrm{mol}^{-1}$ which was $3.7 \mathrm{kcal} \mathrm{mol}^{-1}$ smaller than that for the pentamer. In a similar manner, the measurement of the $T_{\mathrm{c}}$ for the trimer gave a value of $-98^{\circ} \mathrm{C}$. Although the $T_{\mathrm{c}}$ was somewhat lower than the freezing point of pure toluene- $d_{8}$ $\left(-95^{\circ} \mathrm{C}\right)$, the measurement was successful. The $T_{\mathrm{c}}$ and $\Delta v$ for the chloral oligomers from trimer to hexamer are summarized in Table I. $\Delta G^{\neq}$ can be converted to the life time of a one-handed helix at a given temperature; the values at $20^{\circ} \mathrm{C}\left(\tau_{20}\right)$ are included in the table. A linear relation was obtained between $\Delta G^{\neq}$ and $n$ as displayed in Figure 5.

Assignments of the NMR signals were made by two-dimensional techniques. Figure 6 shows a NOESY spectrum of the hexamer. The acetal proton $\mathrm{H}^{1 \mathrm{a}}$ exhibited NOE correlation to the methyl protons $\mathrm{CH}_{3}{ }^{\mathrm{a}}$ (peak I) and to the 
neighboring acetal proton $\mathrm{H}^{2 \mathrm{a}}$ (peak II). It is interesting to note that $\mathrm{H}^{1 \mathrm{a}}$ gave another

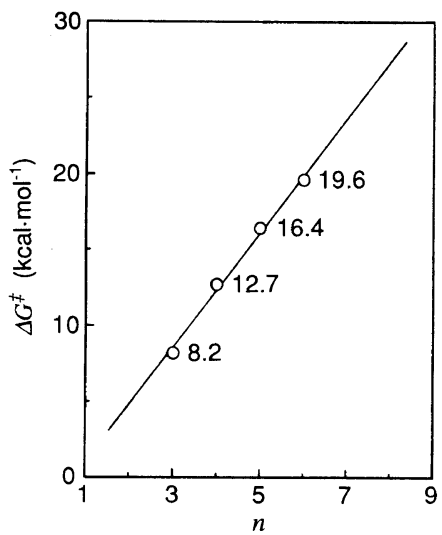

Figure 5. Plot of the activation energy for the helixinversion $\left(\Delta \mathrm{G}^{\neq}\right)$as a function of the degree of polymerization $(n)$ of the symmetrical methoxy-terminated oligomers of chloral 4. correlation to the acetal proton at the remotest position, $\mathrm{H}^{1 \mathrm{~b}}$ (peak III). This correlation peak does not derive from NOE but from the site-exchange between $\mathrm{H}^{1 a}$ and $\mathrm{H}^{1 \mathrm{~b}}$ through the helix-sense inversion. The correlation peaks due to the exchange were distinguishable from those due to the NOE since the former appeared as positive peaks whereas the latter appeared as negative peaks. ${ }^{* 1} \mathrm{H}^{2 \mathrm{a}}$ showed NOE correlations with $\mathrm{H}^{1 \text { a }}$ (peak IV) and one of $\mathrm{H}^{3}$ (peak $\mathrm{V}$, this peak did not have digital resolution enough to differentiate $\mathrm{H}^{3 \mathrm{a}}$ from $\mathrm{H}^{3 \mathrm{~b}}$ ), and the exchange correlation with $\mathrm{H}^{2 \mathrm{~b}}$ (peak VI). Unequivocal assignments of the other proton resonances were also made in a similar manner. The assignments of the ${ }^{13} \mathrm{C}$ NMR signals were made by long-range ${ }^{13} \mathrm{C}-{ }^{1} \mathrm{H}$ COSY experiments (Figure 7). Correlation peaks could be clearly found between the
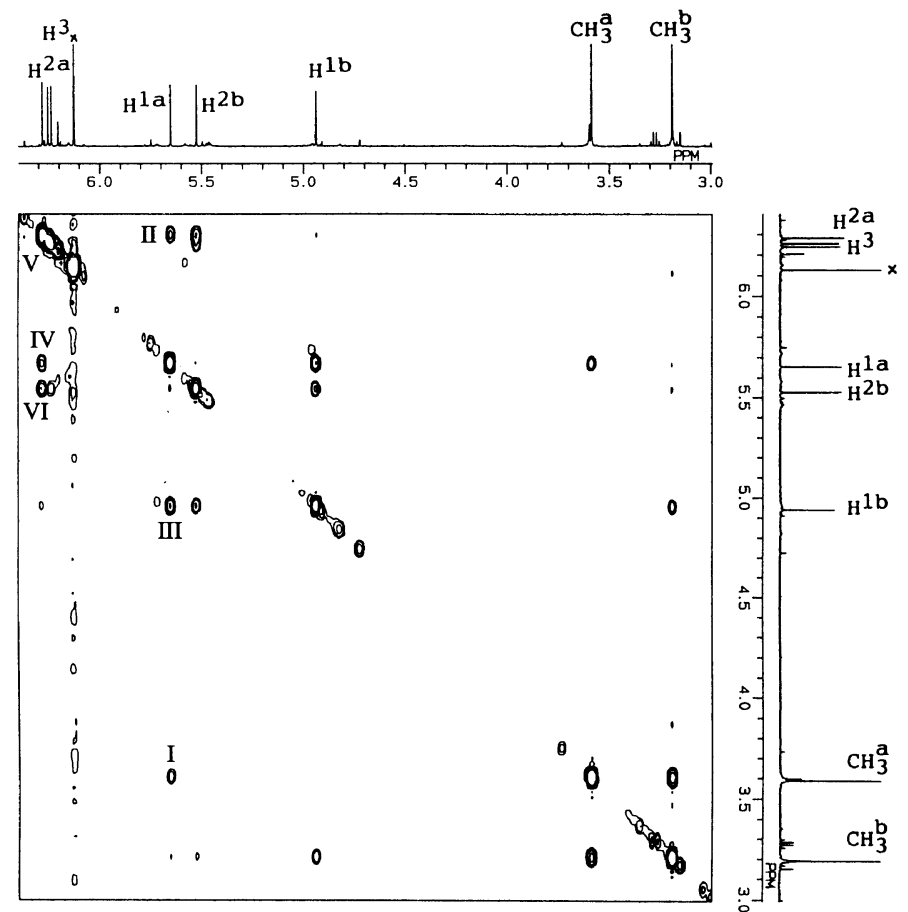

Figure 6. NOESY spectrum of the isotactic hexamer of 4 in toluene- $d_{8}$ at $30^{\circ} \mathrm{C}(500 \mathrm{MHz}$, mixing time $=2.4 \mathrm{~s}$ )

*1 For non-viscous solutions of small molecules, where the extreme narrowing limit applies, the NOE correlation is observed as weak negative peaks. ${ }^{27}$ 

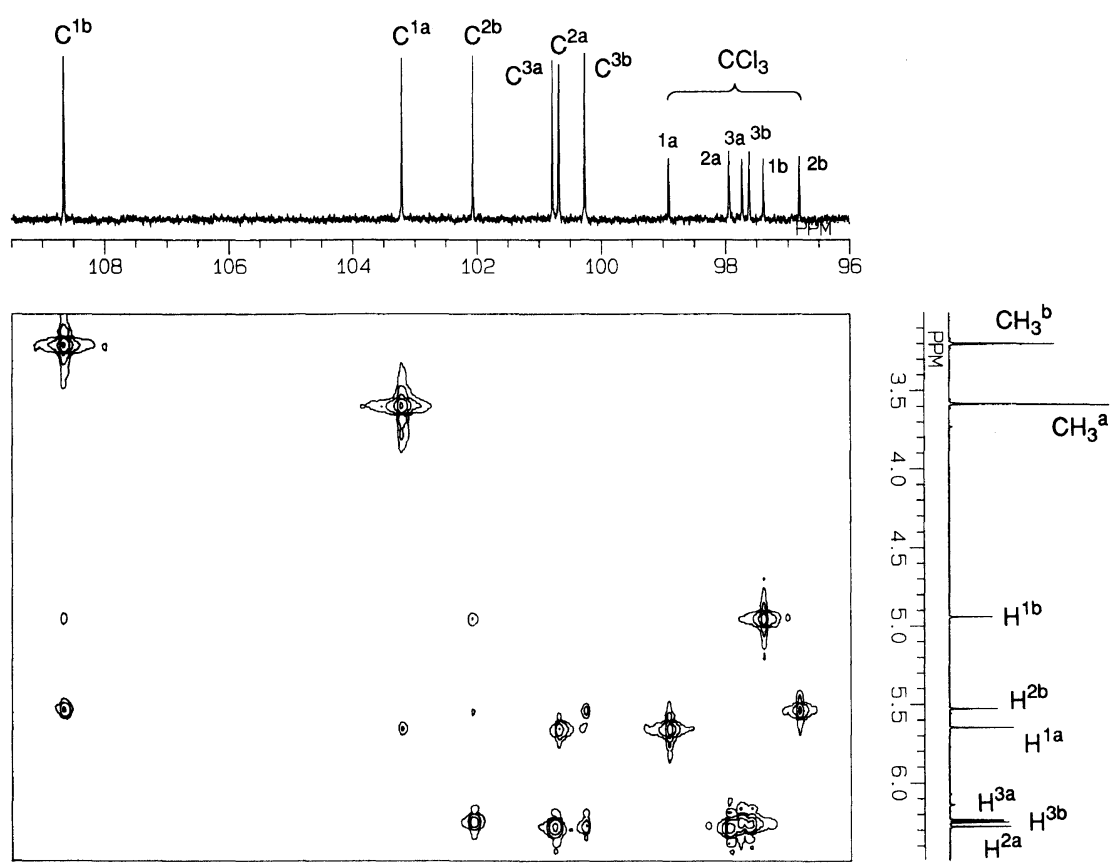

Figure 7. Long-range ${ }^{13} \mathrm{C}-{ }^{1} \mathrm{H}$ COSY (COLOC) of the hexamer of 4 .

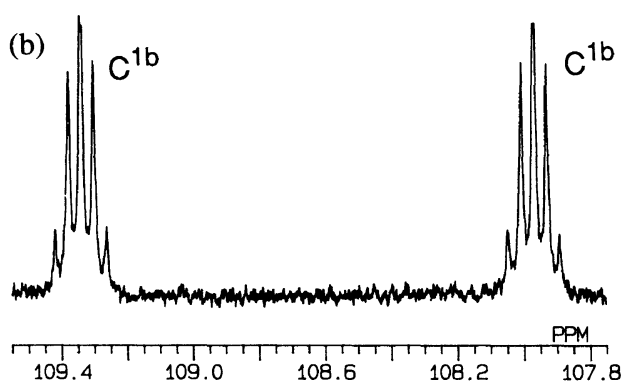

(a)

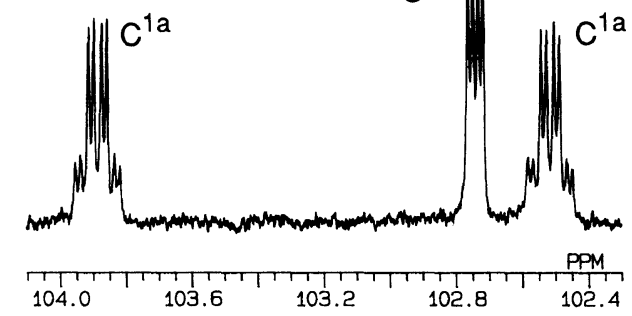

Figure 8. ${ }^{1} \mathrm{H}$-Coupled ${ }^{13} \mathrm{C}$ NMR spectra of the hexamer of 4 in toluene- $d_{8}$ at $30^{\circ} \mathrm{C}$ (the resonances due to the acetal carbon atoms $\mathrm{C}^{1 \mathrm{a}}$ and $\mathrm{C}^{1 \mathrm{~b}}$ adjacent to the methoxy terminal groups, $125 \mathrm{MHz}$ ). methyl protons and the $\mathrm{C}^{1}$ carbon atoms, between the acetal protons and the acetal carbon atoms, and between the acetal protons and the $\mathrm{CCl}_{3}$ carbon atoms.

Figure 8 shows the acetal carbon resonances of the hexamer in the ${ }^{1} \mathrm{H}$-coupled ${ }^{13} \mathrm{C} \mathrm{NMR}$ spectrum measured in toluene- $d_{8}$ at $30^{\circ} \mathrm{C}$. Both the signals due to the acetal carbon atoms $\mathrm{C}^{1 \mathrm{a}}$ and $\mathrm{C}^{1 \mathrm{~b}}$ which are adjacent to the end-groups split into two peaks by the direct coupling from the connected proton $\left[{ }^{1} J\left(\mathrm{C}^{1 \mathrm{a}}-\mathrm{H}^{1 \mathrm{a}}\right)=172.2 \mathrm{~Hz}\right.$, $\left.{ }^{1} J\left(\mathrm{C}^{1 \mathrm{~b}}-\mathrm{H}^{1 \mathrm{~b}}\right)=172.5 \mathrm{~Hz}\right]$. These peaks exhibited further fine splittings due to the longrange ${ }^{3} J(\mathrm{C}-\mathrm{O}-\mathrm{C}-\mathrm{H})$ couplings from the terminal methyl protons $\left(\mathrm{CH}_{3}{ }^{\mathrm{a}}\right.$ or $\left.\mathrm{CH}_{3}{ }^{\mathrm{b}}\right)$ and the acetal proton in the next monomeric unit $\left(\mathrm{H}^{2 \mathrm{a}}\right.$ or $\left.\mathrm{H}^{2 \mathrm{~b}}\right)$. The magnitude of the ${ }^{3} \mathrm{~J}(\mathrm{C}-\mathrm{O}-\mathrm{C}-$ $\mathrm{H})$ between $\mathrm{CH}_{3}{ }^{\mathrm{a}}$ and $\mathrm{C}^{1 \mathrm{a}}(5.0 \mathrm{~Hz})$ is identical with that between $\mathrm{CH}_{3}{ }^{\mathrm{b}}$ and $\mathrm{C}^{1 \mathrm{~b}}$. On the other hand, ${ }^{3} J\left(\mathrm{C}^{1 \mathrm{a}}-\mathrm{O}-\mathrm{C}-\mathrm{H}^{2 \mathrm{a}}\right)(2.0 \mathrm{~Hz})$ differs from ${ }^{3} J\left(\mathrm{C}^{1 \mathrm{~b}}-\mathrm{O}-\mathrm{C}-\mathrm{H}^{2 \mathrm{~b}}\right)(4.4 \mathrm{~Hz})$ as can be seen in Figures $8 \mathrm{a}$ and $8 \mathrm{~b}$. The difference of the coupling constants comes from the Karplus 
type dependence of ${ }^{3} J(\mathrm{C}-\mathrm{O}-\mathrm{C}-\mathrm{H})$ on the dihedral angle $\phi$ in the ${ }^{13} \mathrm{C}-\mathrm{O}-\mathrm{C}-{ }^{1} \mathrm{H}$ arrays. ${ }^{16}$ The relationship can be expressed by the following equation. ${ }^{28,29}$

${ }^{3} J(\mathrm{C}-\mathrm{O}-\mathrm{C}-\mathrm{H})=2.21 \cos 2 \phi-1.03 \cos \phi+3.64$

The acetal backbone of this symmetrical $(R, R, R, S, S, S)$-hexamer is considered to assume a helical structure similar to $1,{ }^{16}$ namely, the repeated $\bar{g}\left(\sim-75^{\circ}\right) s\left(\sim 142^{\circ}\right)$ arrangements from the $\mathrm{CH}^{1 \mathrm{a}}$ side to the $\mathrm{CH}^{1 \mathrm{~b}}$ side. As a consequence, $\phi$ in the $\mathrm{C}^{1 \mathrm{a}}-\mathrm{O}-\mathrm{C}-\mathrm{H}^{2 \mathrm{a}}$ array is estimated as $45^{\circ}$ and that in the $\mathrm{C}^{1 \mathrm{~b}}-\mathrm{O}-\mathrm{C}-\mathrm{H}^{2 \mathrm{~b}}$ array as $22^{\circ}$. Then, ${ }^{3} \mathrm{~J}\left(\mathrm{C}^{1 \mathrm{a}}-\mathrm{O}-\right.$ $\left.\mathrm{C}-\mathrm{H}^{2 \mathrm{a}}\right)$ and ${ }^{3} \mathrm{~J}\left(\mathrm{C}^{1 \mathrm{~b}}-\mathrm{O}-\mathrm{C}-\mathrm{H}^{2 \mathrm{~b}}\right)$ were calculated to be 2.9 and $4.3 \mathrm{~Hz}$, respectively. The values agree essentially with the observed data.

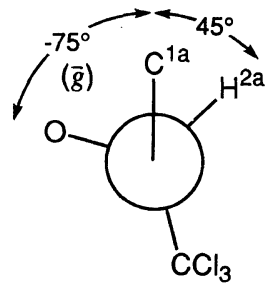

$(R)$-gauche(-)

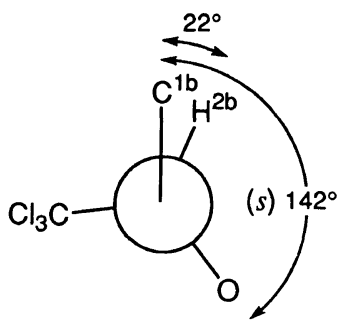

$(S)$-skew $(+)$
Optical Resolution of the Symmetrical Oligomers by HPLC

As can be seen in Figure 5, the $\Delta G^{\neq}$of the chloral oligomer increased linearly with the degree of polymerization $(n)$. The trimer had an inversion barrier of $8.2 \mathrm{kcal} \mathrm{mol}^{-1}$, and the value increased about $3.8 \mathrm{kcal} \mathrm{mol}^{-1}$ for each numerical increase in $n$. By extrapolating this linear $\Delta G^{\neq} v s . n$ plot, we find that the heptamer and octamer have $\Delta G^{\neq}$exceeding 23 and $27 \mathrm{kcal} \mathrm{mol}^{-1}$, respectively. The $\tau_{20}$ estimated from the $\Delta G^{\neq}$was $21 \mathrm{~h}$ for the heptamer and 1.7 years for the octamer. This indicated that the symmetrical oligomers 4 with $n>6$ could be optically resolved at room temperature based entirely on conformational asymmetry (rigidity of the helix).

In order to confirm this supposition, we

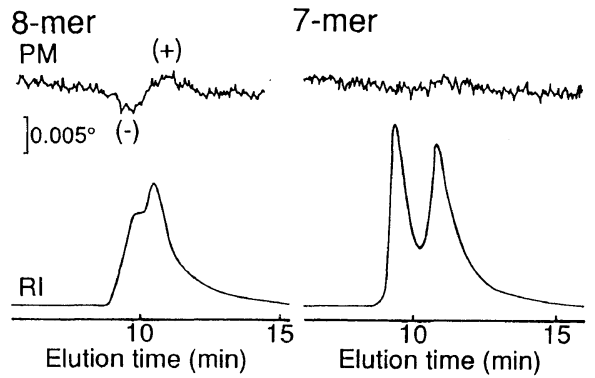

6-mer 5-mer

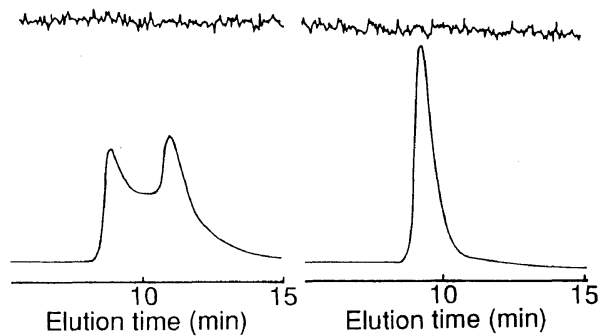

Figure 9. Optical resolution of the symmetrical methoxyterminated oligomers of chloral 4 using the HPLC technique with (+)-poly(triphenylmethyl methacrylate) as the stationary phase $\left(\right.$ at $1^{\circ} \mathrm{C}$, eluent $=$ methanol; $\mathrm{RI}=$ refractive index detection; $\mathrm{PM}=$ polarimetric detection).

attempted the optical resolution of the chloral oligomers by means of HPLC using a chiral stationary phase. Figure 9 shows the elution curves of the oligomers from pentamer to octamer recorded by refractive index (RI) and polarimetric detectors. (+)-Poly(triphenylmethyl methacrylate) was used as stationary phase. The chromatography was conducted at $1^{\circ} \mathrm{C}$. The pentamer was not resolved as it was expected from the small $\Delta G^{\neq}$. On the other hand, chromatograms of the hexamer, the heptamer, and the octamer each displayed two peaks. The elution curve of the hexamer seems to indicate that some racemization occurred during the chromatographic separation. In actual fact, the fractions exhibited no optical activity. Even though the octamer was only partially resolved, it was demonstrated, by polarimetric detection, that the levorotatory helix eluted faster than the dextrorotatory helix. Since the symmetrical oligomers of chloral are the "meso" isomers and have no 
chirality in their primary structures, the optical resolution of the oligomers is direct evidence that a stable conformational asymmetry (helicity) exists in these structures.

\section{Energy Difference between the Two Helical States $(\Delta G)$}

When the isotactic oligomer carries nonidentical end-groups $\left(R \neq R^{\prime}\right)$, each oligomer homologue can have the two enantiomers, e.g., $R, R, \cdots, R$ and $S, S, \cdots, S$ for 1 . The righthanded and left-handed helical conformations in each enantiomer are the diastereomeric states whose free energies differ from one another $(\Delta G \neq 0)$. Hence, it was expected that the two helical states should be observed by NMR at temperatures below $T_{\mathrm{c}}$, provided that both states have a detectable abundance. Actually, only the major helix (the $(\bar{g} s)_{n}$ state for the $R, R, \cdots, R$ isomer) was observed in the case of the $t$-butoxy-initiated, acetyl-terminated oligomer 1 owing to a large $\Delta G .^{16,17}$ The methoxy-initiated, acetyl-terminated oligomer $\mathbf{2}$ and the ethoxy-initiated, methoxy-terminated oligomer 3 were expected to have a smaller $\Delta G$ than 1 because of the similarity of the two

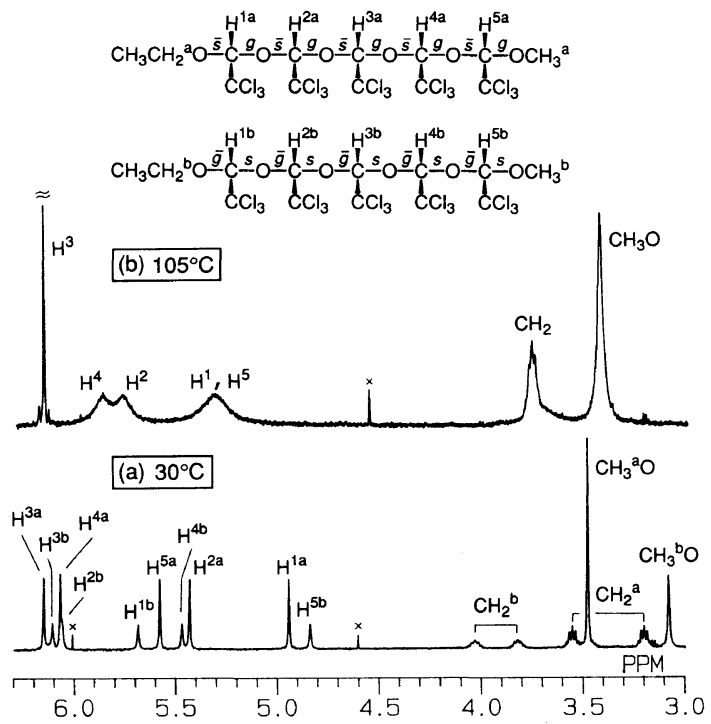

Figure 10. $500 \mathrm{MHz}{ }^{1} \mathrm{H}$ NMR spectra of the chloral pentamer of 3 in toluene- $d_{8}$ at $30^{\circ} \mathrm{C}$ (a) and at $105^{\circ} \mathrm{C}$ (b). end-groups ( $\mathrm{R}$ and $\mathrm{R}^{\prime}$ ) in bulkiness.

The $R / S$ notation depends on the order of priority for the respective acetal carbon atoms and the two end-groups. The $R, R, \cdots, R$ and $S, S, \cdots, S$ notations apply to the isotactic oligomers of 1 and 2 . However, the isotactic oligomers of $\mathbf{3}$ must be denoted explicitly in a way indicating $(1 R, 2 R, 3 R, 4 S, 5 S)$ and $(1 S, 2 S$, $3 S, 4 R, 5 R)$ for the pentamer. For the sake of simplicity, the optical antipode having $(R)$ configuration at the $\mathrm{C}^{1}$ position (the acetal carbon atom adjacent to the end-group " $R$ ") will be represented as the $(R)$-isomer. The absolute configurations for the $(R)$-pentamer of $\mathbf{3}$ and the $(R)$-hexamer of $\mathbf{2}$ are demonstrated in Figures 10 and 11 , respectively.

Figure 10 shows the ${ }^{1} \mathrm{H}$ NMR spectra of the isotactic pentamer of $\mathbf{3}$ measured in toluene- $d_{8}$. When the spectrum was measured at $30^{\circ} \mathrm{C}$ (Figure 10a), the two methoxy resonances $\left(\mathrm{CH}_{3}{ }^{\mathrm{a}} \mathrm{O}\right.$ and $\left.\mathrm{CH}_{3}{ }^{\mathrm{b}} \mathrm{O}\right)$ were observed with an intensity ratio of about $2: 1$. The acetal methine resonances also appeared as two sets of five singlets. The two sets of resonances are attributable to the $(\bar{g} s)_{5}$ and $(\bar{s} g)_{5}$ states for the $(R)$-isomer in the equilibrium (and also to the $(g \vec{s})_{5}$ and $(s \bar{g})_{5}$ states for the $(S)$-isomer). The
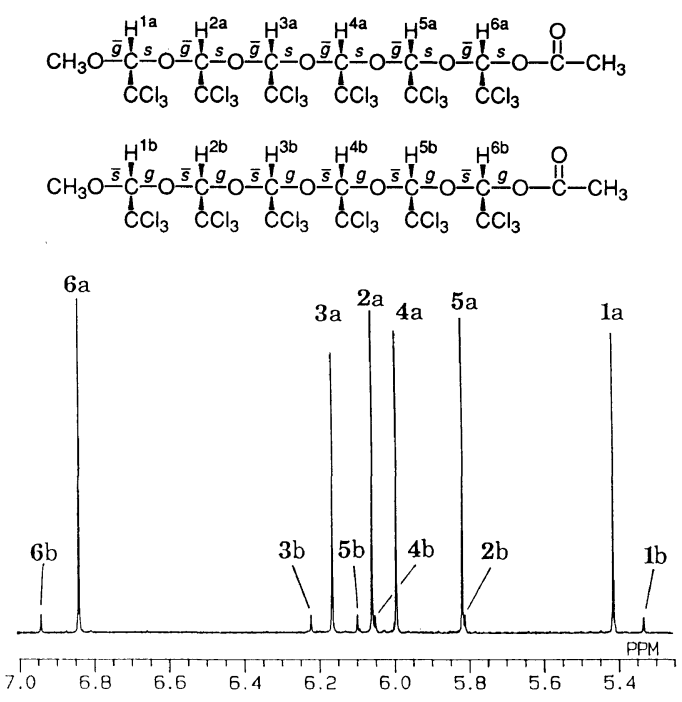

Figure 11. Acetal proton resonances of the chloral hexamer of 2 in $\mathrm{CDCl}_{3}$ at $30^{\circ} \mathrm{C}$ and $500 \mathrm{MHz}$. 
Table II. The ratio $(K)$ and $\Delta G$ of the two helical states $(\bar{g} s)_{n}$ and $(\bar{s} g)_{n}$ for the $(R)$-oligomers of 2 and 3 in $\mathrm{CDCl}_{3}$ at $0^{\circ} \mathrm{C}$

\begin{tabular}{|c|c|c|c|c|}
\hline & \multirow{2}{*}{$(R)$-oligomer } & \multirow{2}{*}{$n$} & \multirow{2}{*}{$K^{\mathrm{a}}$} & \multirow{2}{*}{$\frac{\Delta G^{\mathrm{b}}}{\mathrm{kcal} \mathrm{\textrm {mol } ^ { - 1 }}}$} \\
\hline & & & & \\
\hline 2 & $\mathrm{CH}_{3} \mathrm{O}\left(\begin{array}{l}\mathrm{H} \\
\mathbf{C} \\
\mathrm{C}-\mathrm{O} \\
\mathrm{CCl}\end{array}\right)_{n}^{\mathrm{II}}-\mathrm{CH}_{3}$ & $\begin{array}{l}5 \\
6\end{array}$ & $\begin{array}{l}29.9 \pm 0.9 \\
17.3 \pm 0.4\end{array}$ & $\begin{array}{l}-1.84 \\
-1.55\end{array}$ \\
\hline 3 & 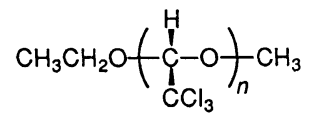 & $\begin{array}{l}4 \\
5 \\
6\end{array}$ & $\begin{array}{l}0.37^{\mathrm{c}} \pm 0.01 \\
0.481 \pm 0.002 \\
0.420 \pm 0.002\end{array}$ & $\begin{array}{l}0.54^{\mathrm{c}} \\
0.398 \\
0.471\end{array}$ \\
\hline
\end{tabular}

two states were indistinguishable at $105^{\circ} \mathrm{C}$ because of the fast exchange (Figure 10b). The conformational equilibrium of this pentamer is expressed as follows for the $(R)$-isomer.

$$
(\bar{s} g)_{5} \stackrel{K}{\rightleftarrows}(\bar{g} s)_{5}
$$

The major conformer at $30^{\circ} \mathrm{C}$ was determined as the $(\bar{s} g)_{5}$ state. This conclusion is based on the fact that the chemical shifts of the $\mathrm{CH}_{3}{ }^{\mathrm{a}} \mathrm{O}$ and $\mathrm{CH}_{3}{ }^{\mathrm{b}} \mathrm{O}$ signals in Figure $10 \mathrm{a}$ are nearly equal to those in Figure 3a. It follows that $\mathrm{CH}_{3}{ }^{\mathrm{a}} \mathrm{O}$ is located at the $\mathrm{g}$-side and $\mathrm{CH}_{3}{ }^{\mathrm{b}} \mathrm{O}$ at the $s$-side, i.e., the resonance sets " $\mathrm{a}$ " and " $\mathrm{b}$ " are due to the $(\bar{s} g)_{5}$ and $(\bar{g} s)_{5}$ conformers, respectively. Judging from the $\Delta G^{\neq}$for the pentamer of 4 ( $c f$. Figure 5), the conformational equilibrium of the pentamer of 3 must be established within seconds at $30^{\circ} \mathrm{C}$. Therefore, the relative intensity of the two sets of NMR signals, $\left[\mathrm{CH}_{3}{ }^{b} \mathrm{O}\right] /\left[\mathrm{CH}_{3}{ }^{a} \mathrm{O}\right]$, corresponds directly to the equilibrium constant $K$.

The oligomers 2 also displayed two sets of ${ }^{1} \mathrm{H}$ NMR signals arising from the two helical conformers. In the case of the hexamer, when measured in chloroform- $d$ at $30^{\circ} \mathrm{C}$, the amount of the major conformer was about 13 times as large as that of the minor conformer (Figure 11). The $\mathrm{CH}_{3}{ }^{\mathrm{a}} \mathrm{O}$ and $\mathrm{CH}_{3}{ }^{\mathrm{b}} \mathrm{O}$ resonances appeared at 3.46 and $3.08 \mathrm{ppm}$ with an intensity ratio of $13: 1$; based on the similarity of the chemical shift of the methoxy resonances among the oligomers of $\mathbf{2 , 3}$, and $\mathbf{4}$, the major conformer for the $(R)$-isomer of $\mathbf{2}$ was found to be the $(\bar{g} s)_{5}$ state. The ratio of the two conformers differed slightly from that determined in toluene- $d_{8}$ at $30^{\circ} \mathrm{C}(K=10.5)$.

The $K$ and $\Delta G$ for the two helical conformers of 2 and $3(n=5,6)$ in chloroform- $d$ at $0^{\circ} \mathrm{C}$ are presented in Table II. The values for the tetramer of $\mathbf{3}$ were determined at $-40^{\circ} \mathrm{C}$. The $\Delta G$ of 3 was in the range of 0.4 to $0.5 \mathrm{kcal} \mathrm{mol}^{-1}$, and was essentially independent on $n$. On the other hand, the $|\Delta G|$ for the hexamer of $\mathbf{2}$ was significantly smaller than that for the pentamer of 2 . The latter result may be interpreted in such a way that the contribution to the conformational energy from the end-groups of a entire molecule decreased with increasing $n$.

From the temperature dependency of $\Delta G$, the thermodynamic constants $\Delta H$ and $\Delta S$ for the hexamers of $\mathbf{2}$ and $\mathbf{3}$ were determined (Figure 12). The $\Delta H$ and $\Delta S$ were obtained as the slope and intercept in the van't Hoff plot $[\ln K=-(\Delta H / R T)+(\Delta S / R)]$. The $\Delta S$ for the hexamer of 2 was nearly equal to $R \ln 2$ $\left(=1.38 \mathrm{cal} \mathrm{K}^{-1} \mathrm{~mol}^{-1}\right)$, indicating that the $(\bar{g} s)_{6}$ state of the $(R)$-isomer has a conformational probability (degrees of freedom) twice as large as the $(\bar{s} g)_{6}$ state. This suggests that 


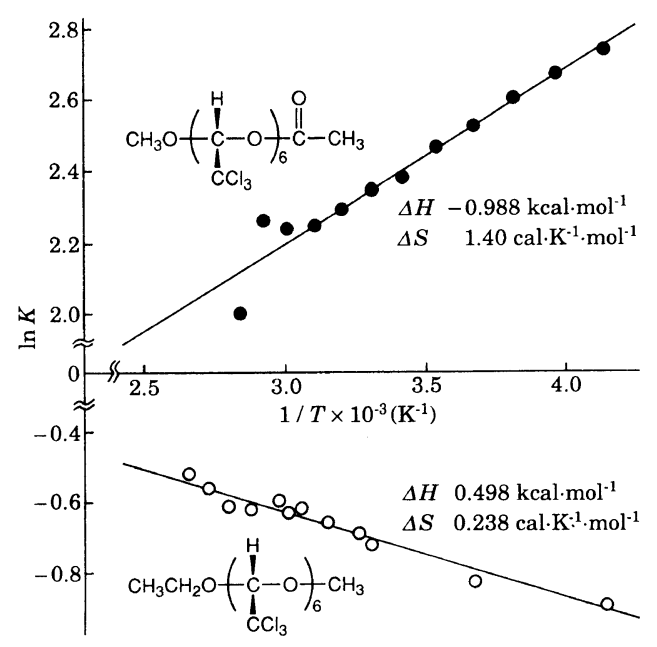

Figure 12. van't Hoff plots for the helix-inversion equilibrium $\left[(s \bar{g})_{n} \rightleftarrows(\bar{g} s)_{n}\right]$ of the $(R)$-hexamers of 2 and 3 in toluene- $d_{8}$.

the acetyl end-group may adopt either syn or anti geometry in the $s$-side whereas only one of them may be allowed in the $g$-side. The $\Delta S$ for the hexamer of $\mathbf{3}$ was small as compared with that for the hexamer of 2.

We have now obtained three examples of the isotactic chloral oligomers ( 1 to 3 ) with $R \neq R^{\prime}$. The $(\bar{g} s)_{n}$ state was the major conformer for the $(R)$-isomers of 1 and 2, which suggests that the acetyl end-group prefers the $s$-side to the $g$-side. The fact that the $\Delta G$ in $\mathbf{1}$ is much larger than the $\Delta G$ in 2 seems to indicate that the $t$-butyl group has a stronger tendency to assume the $\bar{g}$-side as compared with the methyl group. However, this assumption contradicts the result obtained for 3 that the bulkier end-group $\left(\mathrm{C}_{2} \mathrm{H}_{5}>\mathrm{CH}_{3}\right)$ tends to assume the $\bar{s}$-side. It appears that both dipole and steric interactions between the end-groups and the oligomer chain effect the preferred conformation of the chloral oligomers.

Table III shows the results of the molecular mechanics calculations of the $(R)$-pentamers of 2 and 3. The calculations indicate that the $(\bar{g} s)_{5}$ state is the major conformer for $\mathbf{2}$ but is the minor conformer for 3 . These conclusions are consistent with the experimental facts described above. The differences of total energies between the two states agreed quite well with the values of $\Delta H$ in Figure 12. Inspection of the six items on the list of conformational energies (Table III) indicates that the major part $(68 \%)$ of the energy difference between the $(\bar{g} s)_{5}$ and the $(\bar{s} g)_{5}$ states for 3 comes from the contribution of the van der Waals term. On the other hand, it is realized that not only the van der Waals term but also the torsional and dipole terms influence the energy difference between the major and minor conformers for $\mathbf{2}$.

Considerations of the Stability of the OneHanded Helix at the Early Stage of Polymerization

All the oligomers examined in this work have no chirality in the end-groups, and consequently, they were obtained as a $1: 1$ mixture of enantiomeric helices even though each $(R)$ - and $(S)$-isomer prefers one helical-sense over the other. Polymers and oligomers with predominantly or preferentially one-handed helix-sense are produced by the polymerization initiated with chiral initiators. The first addition of a chiral initiator to the monomer is an asymmetric process, and generates one of the $(R)$ - and $(S)$-unimers in excess over the other. This was evidenced by the studies on absolute configurations of the chloral oligomers $(1 \leq n \leq 3)$ obtained by initiation with the lithium alkoxide of $(1 S, 2 R, 4 S)-(-)$-borneol. ${ }^{30}$ Subsequent monomer additions to the unimer are known to be highly isotactic specific, yielding one of the $(R)$ - and $(S)$-oligomers predominantly. It should be noted that these $(R)$ - and $(S)$-oligomers do not necessarily prefer opposite helix-senses on account of the chiral end-group. After the oligomers attained the degree of polymerization exceeding $\sim 6$, further propagation processes were considered to proceed without helix-sense inversion. It is believed $^{12}$ and-there is some evidence ${ }^{4}$ that increased bulk size of the initiating group increases the specificity and may ultimately course unique chiral addition in the first 
Table III. The optimized torsional angles, dipole moments, and conformational energies for the right-handed and left-handed helical states of the $(R)$-pentamers of 2 and 3 obtained by MM2 calculations ${ }^{a}$

\begin{tabular}{|c|c|c|c|c|}
\hline & \multicolumn{2}{|c|}{$\begin{array}{c}(R) \text {-pentamer of } 2 \\
\mathrm{R}=\mathrm{CH}_{3}, \mathrm{R}^{\prime}=\mathrm{CH}_{3} \mathrm{CO}\end{array}$} & \multicolumn{2}{|c|}{$\begin{array}{c}(R) \text {-pentamer of } 3 \\
\mathrm{R}=\mathrm{C}_{2} \mathrm{H}_{5}, \mathrm{R}^{\prime}=\mathrm{CH}_{3}\end{array}$} \\
\hline & $(\bar{g} s)_{5}$ & $(\bar{s} g)_{5}$ & $(\bar{g} s)_{5}$ & $(\bar{s} g)_{5}$ \\
\hline & \multicolumn{4}{|c|}{ Torsional angles/deg } \\
\hline $\mathrm{R}-\mathrm{O}-\mathrm{C}^{1}-\mathrm{O}^{1}$ & -72.54 & -120.69 & -71.04 & -121.74 \\
\hline $\mathrm{O}-\mathrm{C}^{1}-\mathrm{O}^{1}-\mathrm{C}^{2}$ & 126.30 & 74.03 & 126.66 & 70.78 \\
\hline $\mathrm{C}^{1}-\mathrm{O}^{1}-\mathrm{C}^{2}-\mathrm{O}^{2}$ & -69.40 & -131.01 & -68.57 & -131.42 \\
\hline $\mathrm{O}^{1}-\mathrm{C}^{2}-\mathrm{O}^{2}-\mathrm{C}^{3}$ & 134.66 & 70.60 & 134.79 & 69.05 \\
\hline $\mathrm{C}^{2}-\mathrm{O}^{2}-\mathrm{C}^{3}-\mathrm{O}^{3}$ & -72.03 & -132.72 & -72.23 & -134.68 \\
\hline $\mathrm{O}^{2}-\mathrm{C}^{3}-\mathrm{O}^{3}-\mathrm{C}^{4}$ & 133.71 & 73.53 & 134.10 & 73.25 \\
\hline $\mathrm{C}^{3}-\mathrm{O}^{3}-\mathrm{C}^{4}-\mathrm{O}^{4}$ & -68.41 & -132.85 & -69.28 & -133.83 \\
\hline $\mathrm{O}^{3}-\mathrm{C}^{4}-\mathrm{O}^{4}-\mathrm{C}^{5}$ & 133.53 & 57.76 & 132.42 & 70.66 \\
\hline $\mathrm{C}^{4}-\mathrm{O}^{4}-\mathrm{C}^{5}-\mathrm{O}^{5}$ & -75.27 & -99.46 & -72.86 & -124.60 \\
\hline $\mathrm{O}^{4}-\mathrm{C}^{5}-\mathrm{O}^{5}-\mathrm{R}^{\prime}$ & 105.20 & 130.36 & 122.01 & 72.27 \\
\hline $\mathrm{C}^{5}-\mathrm{O}-\mathrm{C}=\mathrm{O}$ & -1.25 & 1.08 & - & - \\
\hline \multirow[t]{4}{*}{$\mathrm{CH}_{3}-\mathrm{CH}_{2}-\mathrm{O}-\mathrm{C}^{1}$} & - & - & -176.97 & 177.82 \\
\hline & \multicolumn{4}{|c|}{ Dipole moments/D } \\
\hline & 4.23 & 4.18 & 6.21 & 6.28 \\
\hline & & \multicolumn{2}{|c|}{ Conformational energies $/ \mathrm{kcal} \mathrm{mol}^{-1}$} & \\
\hline Compression & 6.715 & 6.525 & 6.629 & 6.488 \\
\hline Bending & 14.963 & 14.943 & 14.569 & 14.518 \\
\hline Stretch-bend & 1.629 & 1.594 & 1.574 & 1.542 \\
\hline van der Waals & 3.864 & 5.300 & 5.043 & 4.390 \\
\hline Torsional & 13.375 & 14.476 & 16.597 & 16.505 \\
\hline Dipole & 44.214 & 42.683 & 38.454 & 38.464 \\
\hline \multirow[t]{2}{*}{ Total } & 84.760 & 85.521 & 82.865 & 81.906 \\
\hline & $(-0.761)$ & $(0.000)$ & $(+0.959)$ & $(0.000)$ \\
\hline
\end{tabular}

monomer addition step.

\section{CONCLUSION}

The present study of the conformational stability of "isotactic" chloral oligomers has revealed that a slight difference between the two end-groups such as methoxy and ethoxy groups in an oligomer molecule gives rise to the predominance of one helical conformation over the other. Molecular mechanics calculation was found to be useful in predicting the major helix of choice as well as in estimating $\Delta H$. The activation energy for the helix-sense inversion $\left(\Delta G^{\neq}\right)$has been found to increase linearly with $n$. The linear $\Delta G^{\neq}$vs. $n$ plot suggested that the helix-inversion equilibrium freezes for the oligomers higher than the hexamer level at room temperature. This has been confirmed by the optical resolution of the higher conformational (helical) enantiomers.

The present results have provided the basis for the formulation of kinetics and thermodynamics on the stability of the one-handed helix at the early stage of polymerization.

Acknowledgments. The authors are grateful to Prof. A. Abe (Tokyo Institute of 
Technology) for his kind suggestions in the molecular mechanics calculations. A part of this work was supported by the Grant-in-Aid for Scientific Research (No. 03453118) from the Ministry of Education, Science, and Culture of Japan and by CIBA-GEIGY Foundation (Japan) for the Promotion of Science.

\section{REFERENCES}

1. L. S. Corley and O. Vogl, Polym. Bull., 3, 211 (1980).

2. G. D. Jaycox and O. Vogl, Polym. Commun., 30, 354 (1989).

3. W. J. Harris and O. Vogl, J. Macromol. Sci-Chem., A26, 1067 (1989); A26, 1083 (1989).

4. G. D. Jaycox and O. Vogl, Makromol. Chem., Rapid Commun., 11, 61 (1990).

5. Y. Okamoto, K. Suzuki, K. Ohta, K. Hatada, and H. Yuki, J. Am. Chem. Soc., 101, 4763 (1979).

6. Y. Okamoto, I. Okamoto, and H. Yuki, J. Polym. Sci., Polym. Lett. Ed., 19, 451 (1981).

7. R. J. M. Nolte, A. J. M. van Beijnen, and W. Drenth, J. Am. Chem. Soc., 96, 5932 (1974).

8. P. C. J. Kamer, R. J. M. Nolte, and W. Drenth, J. Am. Chem. Soc., 110, 6818 (1988).

9. Y. Ito, E. Ihara, and M. Murakami, Angew. Chem. Int. Ed. Engl., 31, 1509 (1992).

10. Y. Okamoto, H. Mohri, T. Nakano, and K. Hatada, J. Am. Chem. Soc., 111, 5952 (1989).

11. L. S. Corley, Ph. D. Dissertation, University of Massachusetts, 1979.

12. O. Vogl, J. Macromol. Sci., Pure Appl. Chem., A29, 1085 (1992).

13. . M. M. Green, C. Andreola, B. Muñoz, M. P. Reidy, and K. Zero, J. Am. Chem. Soc., 110, 4063 (1988).
14. S. Lifson, C. Andreola, N. C. Peterson, and M. M. Green, J. Am. Chem. Soc., 111, 8850 (1989).

15. O. Vogl, F. Xi, F. Vass, K. Ute, T. Nishimura, and K. Hatada, Macromolecules, 22, 4658 (1989).

16. K. Ute, T. Nishimura, K. Hatada, F. Xi, F. Vass, and O. Vogl, Makromol. Chem., 191, 557 (1990).

17. K. Ute, K. Oka, Y. Okamoto, K. Hatada, F. Xi, and O. Vogl, Polym. J., 23, 1419 (1991).

18. K. Ute, K. Oka, and K. Hatada, manuscript in preparation.

19. K. Ute, K. Hirose, H. Kashimoto, K. Hatada, and O. Vogl, J. Am. Chem. Soc., 113, 6305 (1991).

20. O. Vogl, H. C. Miller, and W. H. Sharkey, Macromolecules, 5, 658 (1972).

21. J. Zhang, G. D. Jaycox, and O. Vogl, Polymer, 29, 707 (1988).

22. K. Hatada, K. Ute, T. Nakano, F. Vass, and O. Vogl, Makromol. Chem., 190, 2217 (1989).

23. K. Ute, N. Miyatake, T. Asada, and K. Hatada, Polym. Bull., 28, 561 (1992).

24. Y. Okamoto, S. Honda, I. Okamoto, H. Yuki, S. Murata, R. Noyori, and H. Takaya, J. Am. Chem. Soc., 103, 6971 (1981).

25. N. L. Allinger and Y. H. Yuh, Quantum Chemistry Program Exchange, 12, 395 (1980).

26. A. Abe, K. Tasaki, K. Inomata, and O. Vogl, Macromolecules, 19, 2707 (1986).

27. R. R. Ernst, G. Bodenhausen, and A. Wokaun, "Principles of Nuclear Magnetic Resonance in One and Two Dimensions," Clarendon Press, Oxford, 1987, p 516.

28. G. K. Hamer, F. Balza, N. Cyr, and A. S. Perlin, Can. J. Chem., 56, 3109 (1978).

29. R. Yamada and I. Ando, Polym. Prepr. Jpn., 32, 835 (1983).

30. K. Ute, K. Oka, M. Kashiyama, K. Hatada, F. Xi, and O. Vogl, Makromol. Chem., 192, 35 (1991). 